\title{
Providing 4P's in Extraordinary Management Services in Whatever Weather Condition
}

\author{
Ming Kwan ${ }^{1}$, Anthony Kong ${ }^{2} \&$ David Liu ${ }^{3}$ \\ ${ }^{1}$ Faculty of Hospitality and Tourism Management, Macau University of Science and Technology, Avenida Wai \\ Long, Taipa, Macau, China \\ ${ }^{2}$ Department of Communication Design and Digital Media at Hong Kong Design Institute, Hong Kong, China \\ ${ }^{3}$ Faculty of Hospitality and Tourism Management, Macau University of Science and Technology, Avenida Wai \\ Long, Taipa, Macau, China \\ Correspondence: Ming Kwan, Faculty of Hospitality and Tourism Management, Macau University of Science \\ and Technology, Avenida Wai Long, Taipa, Macau. E-mail: mwkwan@must.edu.mo
}

Received: January 16, 2019

doi:10.5539/ijbm.v14n3p104
Accepted: February 12, 2019

Online Published: February 19, 2019

\begin{abstract}
Using the properties management in Park Island, Hong Kong, as a case study, the purpose is to focus on illustrating the significance of providing 4P's "Proactive, Protective, Professional and Passionate" in extraordinary properties management services in whatever weather condition and on whenever situation.

Design/Methodology/Approach - This paper used the Super Typhoon Mangkhut in Sept 2018 in Park Island, Hong Kong, as a case study to illustrate the professionalism exhibited in Park Island, Kai Shing Management Services Limited. The deep thoughts and feelings from residents were quoted and analyzed. Authors conducted twenty-five in-depth semi-structured interviews.

Findings - The inspiring real life experiences from respondents who have been living in Park Island were quoted. It has been reflecting the "PARK ISLAND" spirit and demonstrating the significance of professionalism and extraordinary service performance for crisis management after super typhoon Mangkhut signal No. 10 was hoisted. Providing 4P's "Proactive, Protective, Professional and Passionate" in extraordinary properties management services in whatever weather condition and on whenever situation can gain the trust, respect, appreciation and gratitude from residents to professional property management practitioners.

Practical implications - Based on the insights gained from interviewees, providing 4P's -“Proactive, Protective, Professional and Passionate" in extraordinary properties management services in whatever weather condition and on whenever occasion can exceed residents' expectations and enhance the reputation of the property management company.

Originality/value - This paper urges for the fundamental service philosophy and attitude exhibited from the property management practitioners to deal with crisis management during the adverse weather condition. This paper uses the Super Typhoon Mangkhut in Sept 2018 in Park Island, Hong Kong, as a case study, and the aim of such an episode is to arouse all the properties management companies to strive the best to meet and exceed residents' needs in whatever weather condition and on whenever occasion.
\end{abstract}

Keywords: property management, service management, crisis management

\section{Introduction}

In the service industry like properties management, quality and perception of quality is essential. Thus, the need to deliver quality service is imperative in order to meet the needs of customers and exceed their expectation (Baharum, Nawawi, \& Saat, 2014). The rising demand for higher management quality and more sophisticated facilities means that management services are no longer limited to cleaning, security and maintenance. In some properties, management companies even provide recreational services, food and beverages and transportation (KSMS, 2019). Nowadays, properties management covers lots of facets from providing strict cleaning standard, monitoring 24-hour reliable security services, keeping maintenances, creating beautiful landscaping, operating clubhouses, planning and coordinating recreational activities, planning and organizing events, planning, 
implementing and educating residents to live green...etc..

Thus, properties management is a very demanding and challenging profession (Baharum, Nawawi, Saat, 2009). It involves organizing an efficient system as well as directing, coordinating and controlling all the skills available towards maintaining the property value and at the same time ensuring maximum protection of its fabric from deterioration and wastage through proper upkeep and maintenance (Scarrett, 1986). The objective is to maximize the value of customers' properties. The requirement for high standard of service quality in properties management has grown through the years due to the fact that customers have become more demanding in an increasingly competitive business environment. In addition, due to the multidimensional characteristic of customers that in turn will be influenced by culture, subculture, social class, family, friends, educational backgrounds, religion, experiences, mass media, social media, and advertising. In this regard, it is very challenging to manage the diversified customers with different needs and expectations.

Despite all the challenges for both the management and frontline staff of properties management are facing, we appreciate that they are demonstrating the motto of "WE SERVE YOU BEST!" While the most impressive thing we have seen and felt is that they are providing services from their hearts which is the golden rule and fundamental philosophy to win the trust, appreciation and respect from residents' bottom of their hearts. They have been providing 4P's - "Proactive, Protective, Professional and Passionate" in extraordinary properties management services in whatever weather condition and on whenever occasion!

This study intends to examine and analyze how to strengthen extraordinary properties management services for practitioners as they are under the challenges of managing customers' expectations in whatever weather conditions and on whenever occasions that will supplement existing research and expand the findings into untapped areas. The value of this study is that it helps to answer questions concerning how to strengthen extraordinary properties management services performances in whatever critical weather conditions for properties management practitioners.

\section{Park Island Background}

Park Island, named as "the leisure vacation island", is a private residential area situated in Ma Wan, which is located in the north-east part of Ma Wan. Park Island consists of over 5,000 residential units in 35 blocks with 3 large clubhouses covering an area of over 126,000 sq.m. In Park Island, over 40,000 sq.m are covered with greenery with gardens and mini farms, taking up nearly $40 \%$ of the site area. Since vehicle restrictions are enforced in Ma Wan to limit the emissions, the project by and large is described as a "pollution-free green city" which promotes one-stop green building and management (Chan, 2012). It is regarded as the first largest ecofriendly residential area which covers a large green space since planning (Chan, 2012). The management is dedicated to plan, implement and educate the residents through various environmental protection programs, workshops and events. Green concepts have applied in property planning, design, resources purchasing, architectural work, gardening, daily management operation and management as well as clubhouses activities and events management.

\section{Literature Review}

According to Mahatma Gandhi (Nair, 2009), the father of India, "A customer is the most important visitor on our premises; he is not dependent on us. We are dependent on him. He is not an interruption in our work. He is the purpose of it. He is not an outsider in our business. He is part of it. We are not doing him a favour by serving him. He is doing us a favor by giving us an opportunity to do so". Although Mahatma Gandhi was not the father of marketing, he was the father of India, and his wisdom and insight from this statement can still be applied in properties management.

In the service industry like property management, quality and perception of quality is essential. Service quality is an abstract and elusive concept because of the well-known distinctive natures and characteristics of services which is intangibility, perishability, heterogeneity, and inseparability of production and consumption (Zeithaml et al, 1985; Rust et al, 1996; Kotler and Armstrong, 2001). Thus, quality can vary from person to person, and from situation to situation (Kandampully, 2002).

Perceived service quality was defined as the difference between customer expectations and perceptions or also known as gap analysis (Parasuraman et al, 1985; 1988). The gap analysis model is based on the expectancy disconfirmation theory. Expectancy disconfirmation theory predicts that customers will judge that quality is low if performance does not meet their expectations and quality increases as performance exceeds expectations (Oliver, 1993). Hence, customers' expectations serve as the foundation on which service quality will be evaluated by customers. In addition, as service quality increases, satisfaction with the service and intentions to 
reuse the service increase.

\section{Methodology and Research Methods}

Research on service quality contributions has traditionally employed a variety of deductive processes, testing a plethora of hypotheses and pre-determined theories. Service quality researchers have typically approached the problem from a positivist perspective, utilizing quantitative research techniques such as surveys and questionnaires, and processing data with the help of statistical data analysis tools. While mostly deductive in nature, such research tools tend to measure a set of predetermined hypotheses, searching for answers to the "what" questions and not allowing for any additional factors to enter the researcher's process of reasoning (Yin, 1994). Participants in the events context have been shown to demonstrate a multitude of contributions and it is very likely that their attitudes, behaviors, perceptions and experiences of service quality differ. In order to gain a degree of emotional depth, which is not possible to achieve simply by analyzing quantitative data, a qualitative research approach has been chosen as a more appropriate research strategy. Qualitative research is considered to be "concerned with understanding things rather than with measuring them" (Gordon \& Langmaid, 1988, p. 2), whereby the "subjectivity and the authenticity of human experience" (Silverman, 2010, p. 138) allows the researcher to gain an insight into the different meanings, perceptions, feelings and attitudes of research subjects (Holloway et al., 2010; Veal, 2006).

The setting for the present study was the properties management performance in Park Island, Hong Kong. The sample group comprised 10 female and 15 male respondents, all aged 31-50. Their education levels were all postgraduate.

Data collection took place in Park Island. The researcher undertook one-to-one in-depth semi-structured interviews lasting approximately 40-60 minutes, at a nearby café. Participants were given information about the purpose of the study and written consent was obtained. Topics and questions were designed to elicit responses regarding each participant's attitude, feelings, perceptions and views towards properties management services. Further questions and prompts were included to enquire their feelings, perceptions and attitudes for the services they have experienced. The interviews were digitally recorded and summaries were written up. Responses were analyzed using manual coding, scanning the recordings and flagging emergent themes and common views (Veal, 2006). Finally, the results were grouped into similar conceptual areas according to prevalent themes.

\section{Findings and Discussion}

Super Typhoon Mangkhut has been the highest typhoon warning issued and the most intense storm in Hong Kong's history caused a record storm surge, uprooted some 1,500 trees, and left hundreds of windows smashed all over the city (SCMP, 2018). Typhoon Mangkhut has strong winds smashed through and destroyed many of Park Island's facilities and a vast amount of trees. Regardless the extreme adverse weather condition, I am very grateful that the frontline staff of the Park Island Management Service Office (MSO) had stayed in their posts professionally despite the typhoon signal Number 10's hoisting. No transport was available in and out, and over 100 staffs had worked for 36 hours continuously. They had worked extremely hard for one mission: that is guarding the lives and properties of all Park Island residents. The inspiring real life experiences from respondents who are living in Park Island are quoted. It has been reflecting the "PARK ISLAND" spirit and demonstrating the significance of service quality for crisis management after super typhoon Mangkhut signal No. 10 was hoisted. The excerpts below showcase the professionalism from the frontline staff who carried their duties when typhoon Mangkhut signal No. 10 has been hoisting.

"Because I was at 28/F during Typhoon Mangkhut, which was historic in terms of strength and the destruction it caused. The lobby staff performed admirably. I believe some of the staff stayed over in the Park Island".

"I saw the people of Block 13 really pulled through for our amazing lobby people. I've seen people all day helping to mop and the desk is full of foods and drinks! Well done team block 13!”

"I was very grateful for all the staff who worked over 36 hours and even stayed in Park Island. I gave the lobby staff some foods and drinks to express my sincere care and support”.

"As a resident, I am glad to see the Owner Committee had expressed their sincere gratitude and appreciation to all on-duty staff, including those working in the management office, clubhouses, and all maintenance and security guard staff. They purchased some crystal pears at their own cost and presented and praised them during the morning briefing session on 21 September 2018 as a token of deep appreciation to their professionalism and devoted attitude during adverse weather conditions".

"Under the typhoon signal No. 10, residents made hot meals and invited the frontline staff to use their washrooms and even let them take a rest for overnight. It was touching to see the mutual care, trust and rapport 
care has been built over the years as if we were family members. In fact, we are living and working in this wonderful big family called "Park Island family".

The management and frontline staffs were fearless to the storm and put their great endeavor to keep performing all of their duties no matter big or small to ensure the safety and security of residents in critical moments.

Customers expect efficient and professional attitudes to handle tasks, and humanistic and hearty attitudes to handle customers' safety and feelings. The real case below illustrates the importance of performing 4Ps “Proactive, Protective, Professional and Passionate" property management services in whatever weather condition and on whenever Occasion. Such services were especially important in the recovery process just when super typhoon Mangkhut signal No. 10 was cancelled.

"Mr. Matthew Chan, Assistant Manager of Park Island, had shown his "PARK-I" services which means "Passionate, Attentive, Responsive, Kind" and "I can do my best" attitude and assistance to my sister Amy and her baby to be born in Park Island. After hoisting Super Typhoon Mangkhut Signal No. 10 in mid-September 2018, Amy found broken windows and water seepage from defective external walls outside four rooms. She felt angry to see those defects after spending huge amount of money moving from one flat to another flat just for waiting to welcome her baby to be born to move in. She has renovated the new apartment in order to provide the best living condition for her baby. At that moment, she was pregnant for 29 weeks. She was very worried as time for her pregnancy's due day was approaching. Luckily, we are grateful to Mr. Matthew Chan to handle this incident closely. He checked this incident carefully in person with a technician. We felt amazing that Mr. Matthew Chan had handled the quotation procedures for appointing and monitoring the contractor in an extremely efficient and effective manner. We are very grateful to his professional, prompt and passionate attitude. He has shown concern not only for the safe building conditions of the external walls, but also for the safety and health of Amy and her baby to be born. As Ma Wan is a restricted zone and traffic control has been applied 24 hours every day, taxi is not permitted to access to Block 5 area even in emergency conditions that were strictly regulated by the Transport Department. We reserved a medical service at Union Hospital, a private hospital in Tai Wai for Amy's baby delivery. We did not prefer calling ambulance as it would send Amy to public hospital. Thus, we sent an email to raise our concern to Mr. Matthew Chan again. Whereas, we were very delighted to receive Mr. Matthew Chan's prompt email reply with a detail table to list out various ways to depart from Park Island to Union Hospital. He analyzed the pros and cons of every transportation options in a restricted time period clearly. He is so attentive and dedicated to follow our inquiries no matter big or small issues in a thoughtful manner.

"We appreciate not only for his efficient and professional attitude to handle task, but also for his humanistic and hearty attitude to handle customers' safety and feelings in such sincere manners. Matthew Chan is so caring to follow up the external walls and my health condition, he always speaks in a very caring tone. He came to resident's apartment to check the repairing progress in a very attentive and responsible way. He explained to my father in law patiently. He did final checking to ensure the standard of the repaired external walls".

"I am so grateful for Mr. Matthew Chan 's caring manner extended to me as well as his highly efficient postcrisis management after Super Typhoon Mangkhut Signal No. 10 was hoisted that damaged many facilities in apartments and public areas. On behalf of my baby to be born and my husband, we would like to let Mr. Matthew Chan know how much we appreciate and are grateful for his passionate and professional assistance".

Customers appreciate not only for the handling of this single case after Super Typhoon Mangkhut Signal No. 10 was hoisted, but also for all his great efforts paid in managing properties and facilities under whatever weather conditions and on whenever situations. Most importantly, he strives the best to meet customers' need and exceed customers' expectations in such a heart-warming way. His action demonstrated that property management is not just focusing on functional, technical and image issues, but also for taking care of residents' psychological conditions such as feelings and emotions.

Another real case below illustrates the importance of performing 4Ps $\sim$ "Proactive, Protective, Professional and Passionate" Property Management Services even out of the scope of normal duties.

Mr. Jacky Chan, Assistant Property and Facility Manager, Mr. Norman Lam and a technician came to my apartment to check the mal-functioned LED signage at my door entrance. Even it could not be fixed as it was not a public facility, he was willing to investigate the root cause of the problem thoroughly for 32 minutes and provided a small memo that has a list of qualified companies to fix the signage.

Even though the owner is responsible for contact external companies to change the new LED signal board, it is very professional that they investigated the root causes and explained in a very professional, thoughtful and clear 
way. They gave the resident a small memo which is a recycle paper to list some reliable maintenance companies. From this example, they demonstrated the importance of environmental friendly, professional investigation and extraordinary services performance.

\section{Conclusions and Recommendations}

To conclude, providing 4P's $\sim$ "Proactive, Protective, Professional and Passionate" in extraordinary properties management services and demonstrating the spirit of "PARK ISLAND" in whatever condition and on whenever occasion has been demonstrated in Park Island's case.

The spirit of "PARK ISLAND" is

P-Passionate,

A-Attentive,

R-Responsive,

K-Knowledgeable,

I-Industrious,

S-Sincere,

L-Loving,

A-Affective

N-Naturalistic,

D-Dedicated.

Based on the above case study, we learnt that the extraordinary service performance is not just performed in a single case under specific occasions. It is all about providing continuous services from the hearts of management staff throughout the years in whatever fine or adverse weather conditions, on whenever calm or challenging moments, in ordinary or special days. We are grateful to Park Island's management for their dedicated efforts to take care of our properties and provide extraordinary services in 24 hours, 7 days in a week, 365/366 days in a year.

\section{Recommendations to Properties Management Companies}

1. To strengthen and nurture a caring organizational culture to all services representative from their hearts.

2. To provide regular training to enhance crisis management.

3. To conduct monthly sharing sessions to strengthen the mutual support among team members.

4. To demonstrate the spirit of "Park Island"!

5. Most importantly, to continue to providing 4P's - "Proactive, Protective, Professional and Passionate" in extraordinary properties management services in whatever weather condition and on whenever occasion!

\section{Limitations}

Like all research, this study has a number of limitations which the authors attribute to the relative weakness of interviews to present valid, reliable and trustworthy empirical evidence. Consequently, it is recognized that the results of this study present a snapshot of thoughts and feelings amongst the residents in Park Island. Although the authors make no claims regarding the generalization of the results, this study has indicated a concentration of the service quality of properties management in Park Island. This finding should be of interest to properties management companies which strive to provide quality properties management services to exceed customers' expectations.

\section{Future Research}

This study provides a number of directions for future research. Work can focus on identifying the barriers to implementing programs of service quality as well as customers' satisfaction and ways to overcome those barriers. In addition, efforts should be made to narrow down the gap of perceptions between customers and property managers. Also, future research should also go beyond the dimensions investigated in this research to include other dimensions of quality, particularly culture which may be challenging in a multiracial country. Lastly, future research can also explore new techniques that provide meaningful insights into service quality and customers' satisfaction in crisis management. 


\section{References}

Baharum, Z. A., Nawawi, A. H., \& Saat, Z. M. (2009). Assessment of property management service quality of purpose built office buildings. International Business Research, 2(1), 162.

Chan, S. (2012). A study on green housing management: how can housing managers' best leverage green initiatives for sustainable development. (Thesis). University of Hong Kong, Pokfulam, Hong Kong SAR. http://dx.doi.org/10.5353/th_b4833982

Hogan, J. (2008). My definition of hospitality. What's yours? Hotel Online News for the Hospitality Executive.

Holloway, I., Brown, L., \& Shipway, R. (2007). Meaning not measurement: using ethnography to bring a deeper understanding to the participant experience of festivals and events, International Journal of Event and Festival Management, 1(1), 74-85.

Kandampully, J. (2002). Services Management: The New Paradigm in Hospitality. Pearson Education Australia.

Naik, J. R. K, Anand, B., \& Bashir, I. (2013). An empirical investigation to determine patient satisfaction factors at tertiary care hospitals in India. International Journal of Quality and Service Sciences, 7(1), 2-16.

Nair, S. R. (2001). Consumer Behavior in Indian Perspectives (1st ed.). Mumbai, Himalaya Publication, pp.3

Oliver, R. L. (1993). A Conceptual Model of Service Quality and Service Satisfaction: Compatible Goals, Different Concepts. In Swartz, T.A., Bowen, D.E. \& Brown, S.T. (Eds.), Advances in Services Marketing and Management. Greenwich, Connecticut: JAI Press, pp.65-85.

Parasuraman, A. (1998). Customer service in business-to-business markets: an agenda for research. Journal of Business \& Industrial Marketing, 13(4/5)309-321

Parasuraman, A., Zeithaml V. A., \& Berry, L. L. (1988). SERVQUAL: A multiple-item scale for measuring consumer perceptions of service quality. Journal of Retailing, 64(1), 12-40.

Parasuraman, A., Zeithaml, V. A., \& Berry, L. L. (1985). A Conceptual Model of Service Quality and Its Implications for Future Research. Journal of Marketing, 49(Fall), 41-50.

Parasuraman, A., Zeithaml, V. A., \& Berry, L. L. (1988). Servqual: A Multiple-Item Scale for Measuring Customer Perceptions'. Journal of Retailing, 64(1), 12-41.

Parasuraman, A., Zeithaml, V. A., \& Berry, L.L. (1985). A conceptual model of service quality and its implications for future research. Journal of Marketing, 49, 41-50.

Reeves, C. A., \& Bednar, D. A. (1994). Defining quality: alternatives and implications. Academy of Management Review, 19(3), 19-45.

Reichheld, F. F., \& Sasser, W. E. (1990). Zero defections: quality comes to services. Harvard Business Review, $68(5), 105-111$.

Rust, R. T., Zahorik, A. J., \& Keiningham, L. T. (1996). Service Marketing. New York, NY.: HarperCollins College Publishers.

Saleh, F., \& Ryan, C. (1991). Analysing service quality in the hospitality industry using the SERVQUAL model. Service Industries Journal, 11(3), 324-345.

Scarrett, D. (1983). Properties Management. London, New York E. \& F. N. Spon

Schwenker, L. (1999). Measure twice, cut once. Journal of Property Management, 64(2). 78-83.

Sebastianelli, R., \& Tamimi, N. (2002). How product quality dimensions relate to defining quality, International Journal of Quality \& Reliability Management, 9(4), 442-453.

Silversman, J. R. (2004). Professional Event Coordination. John Wiley \& Sons Inc. New Jersey.

South China Morning Post. (2018). Retrieved from https://www.scmp.com/news/hong-kong/healthenvironment/article/2164523/its-official-typhoon-mangkhut-was-most-intense

Tse, D. K., Nicosia, F. M., \& Wilton, P. C. (1990). Consumer satisfaction as a process. Psychology and Marketing, 7(3), 177-193.

Turan, A., \& Bozaykut-Bük, T. (2016). Analyzing perceived healthcare service quality on patient related outcomes. International Journal of Quality and Service Sciences, 8(4), 478-497.

Van Doorn, J., \& Verhoef, P. C. (2008), Critical Incidents and the Impact of Satisfaction on Customer Share," Journal of Marketing, 72(4), 123-142. 
Veal, A. J. (1994). Research Methods for Leisure and Tourism: A Practical Guide (3rd ed.). Pearson Education.

Walter, U., \& Edvardsson, B. (2012). The physical environment as a driver of customers' service experiences at restaurants. International Journal of Quality and Service Sciences, 4(2), 104-119.

Yin, R. K. (1994). Case Study Research: Design and Methods (2nd ed.). Sage, Thousand Oaks, CA.

Zeithaml, V. A., Parasuraman, A., \& Berry, L. L. (1990). Delivering Quality Service. New York: Free Press.

\section{Copyrights}

Copyright for this article is retained by the author(s), with first publication rights granted to the journal.

This is an open-access article distributed under the terms and conditions of the Creative Commons Attribution license (http://creativecommons.org/licenses/by/4.0/). 